\title{
Emerging role for leucine-rich repeat-containing G-protein-coupled receptors LGR5 and LGR4 in cancer stem cells
}

This article was published in the following Dove Press journal:

Cancer Management and Research

24 March 2014

Number of times this article has been viewed

\author{
Susumu Nakata' \\ Emma Phillips ${ }^{2}$ \\ Violaine Goidts ${ }^{2}$ \\ 'Division of Oncological Pathology, \\ Aichi Cancer Center Research \\ Institute, Nagoya, Japan; ${ }^{2}$ Division \\ of Molecular Genetics, German \\ Cancer Research Center, Heidelberg, \\ Germany
}

\begin{abstract}
The concept of cancer stem cells has gained considerable interest in the last few decades, partly because of their potential implication in therapy resistance. However, the lack of specific cellular surface markers for these cells has impeded their isolation, making the characterization of this cellular subpopulation technically challenging. Recent studies have indicated that leucine-rich repeat-containing G-protein-coupled receptor 4 and 5 (LGR4 and LGR5) expression in multiple organs may represent a global marker of adult stem cells. This review aims to give an overview of LGR4 and LGR5 as cancer stem cell markers and their function in development.
\end{abstract}

Keywords: glioblastoma, colorectal cancer, tissue stem cell marker

\section{The concept of cancer stem cells}

The clonal nature of most malignant tumors is well established. Several studies have shown, however, that as many as 1 million murine or human tumor cells are required to transplant a new tumor from an existing one, although exceptions have been described in melanoma, for example, from which one single cell can form a new tumor. ${ }^{1,2}$ The stochastic model proposes that every cell in the heterogeneous cancer cell population can equally form tumors (Figure 1A). ${ }^{3}$ An alternative point of view is given by the hierarchical model describing a small cell population within the tumor capable of self-renewal and thereby forming tumors with a heterogeneous cell population (Figure 1B). ${ }^{3}$ The complex model is the most recent idea explaining tumor progression. It assumes that several cancer stem cell (CSC) populations with genetic and epigenetic changes coexist. Genetic mutations would be able to produce completely new cell populations, while epigenetic changes might enable cells to form progeny with a limited fate (Figure 1C). ${ }^{4-6}$

If the stochastic model is correct, then tumor cells are biologically homogeneous, and genetic or epigenetic programs that allow for tumorigenesis are operative in the majority of cells that comprise a tumor. The hierarchical model, however, predicts that the tumor cells are functionally heterogeneous and that quantitatively, the only cells capable of tumorigenesis are a small subpopulation within the tumor bulk. In the 1990s, studies provided strong evidence for the latter hypothesis in acute myeloid leukemia, demonstrating that these tumors evolve from stem cells in the bone marrow. ${ }^{7-9}$ This concept was then expanded to other hematopoietic malignancies, such as chronic myeloid leukemia, ${ }^{10,11}$ multiple myeloma, ${ }^{12}$ and lymphoma. ${ }^{13}$

At the apex of the hierarchy, so-called CSCs are defined by their ability to self-renew and differentiate. In the meantime, strong evidence suggests the existence of this rare
Correspondence: Violaine Goidts Division of Molecular Genetics, German Cancer Research Center, Im Neuenheimer Feld, 280 69I20, Heidelberg, Germany

Tel +49 622I 424635

Fax +496221424639

Email v.goidts@dkfz.de 
A

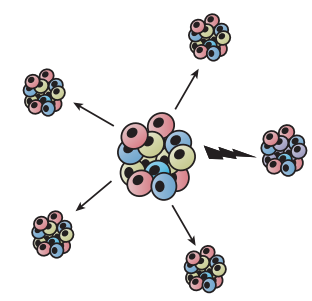

B

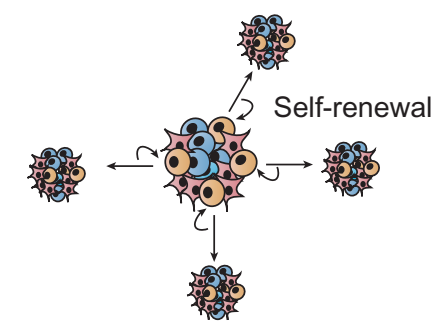

C

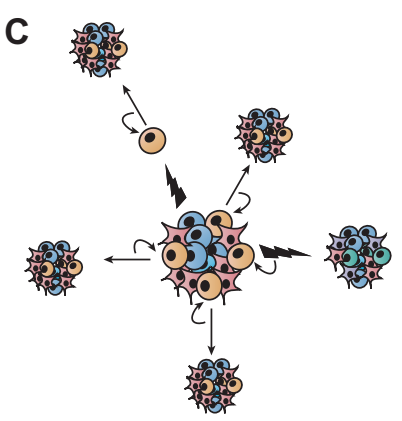

Figure I Sources of heterogeneity within cancer. (A) The stochastic model postulates that all tumor cells are equally capable of self-renewal or differentiation, and are tumorigenic. Tumor heterogeneity is achieved through genetic and/or epigenetic alterations (indicated by flashes). (B) In the hierarchical model, also called the cancer stem cell model of tumor growth, only a subset of tumor cells, the so-called cancer stem cells, has the ability to self-renew, and these cells give rise to committed progenitors with limited proliferative potential, which eventually terminally differentiate. (C) Extending the two concepts, the complex model suggests that epigenetic changes potentially due to micro-environmental factors can influence the tumor cell phenotype and function and thereby can also affect tumor heterogeneity.

and highly tumorigenic CSC population in several major solid cancers, including brain, colon, and breast carcinomas. ${ }^{14}$ This subpopulation of cells has a capacity for self-renewal and multi-lineage differentiation, known features of non-CSCs. Technically, these characteristics have been demonstrated by transplantation assay using immunocompromised mice, combined with enrichment of a particular cell population, typically using cell surface marker expression such as cluster of differentiation (CD)44, EpCAM (epithelial cell adhesion molecule), and CD133. ${ }^{15}$

Recently, stem cell-specific gene-expression signatures have helped to provide further insights into deregulated genes and pathways in CSCs, resulting in improved phenotypic characterization. ${ }^{16}$

\section{G-protein-coupled receptors and their role in cancer signaling}

G-protein-coupled receptors (GPCRs) are transmembrane proteins, which, upon ligand binding, activate cytoplasmic G-proteins that stimulate several enzymes (Figure 2A and B). The G-protein-coupling specificity of each receptor defines the nature of the downstream signaling pathway.

GPCRs contribute to many cellular functions, such as angiogenesis, tissue repair, inflammation, and indeed, cancer. ${ }^{17}$ In fact, in addition to constitutively activating mutations of GPCRs and G-proteins, many tumors harbor overexpression of these receptors, which are activated by agonists released by stromal cells. ${ }^{17}$

\section{The GPCRs LGR5 and LGR4}

LGR4 and LGR5 (leucine-rich repeat-containing GPCR 4 and 5), also known as GPR48 and GPR49, respectively, are members of the largest family of cell-surface molecules involved in signaling, the GPCRs.
The LGR5 gene is $\sim 144 \mathrm{~kb}$ long and is located on chromosome 12 at position $12 \mathrm{q} 22-\mathrm{q} 23$. LGR4 is $\sim 107 \mathrm{~kb}$ long and is found on chromosome 11 at position 11p14-p13. Both proteins contain seven transmembrane domains (Figure 3). Experimental evidence shows that the mature receptor proteins contain up to 17 leucine-rich repeats, each composed of 24 amino acids. These proteins were identified as putative glycoprotein receptors because they are $30 \%-40 \%$ homologous to the luteinizing hormone, follicle-stimulating hormone, and thyrotropin receptors, which contain only nine leucine-rich repeats. ${ }^{18}$

For several years, the molecular functions and the ligands of LGR4 and LGR5 were unknown. Together with LGR6, they were considered to be "orphan" receptors. Recently, however, several groups have identified the R-spondins, soluble protein modulators of the canonical $\mathrm{Wnt} / \beta$-catenin signaling pathway, as ligands for LGR5. ${ }^{19}$ After binding R-spondin, LGR5 forms a protein complex with frizzled lipoprotein receptor-related proteins 5 and 6 (LRP5/6), which positively regulates Wnt signaling. Recent analysis of crystal structures of an R-spondin fragment and LGR5 ectodomain revealed the mode of binding as a pair of heterodimers..$^{20}$ In addition, anti-LGR5 antibody-mediated modulation of the Wnt reporter suggests a direct role of the R-spondin-LGR5 complex in Wnt pathway regulation, rather than indirectly via a tertiary protein complex together with LRPs or frizzled receptors. Thus, the R-spondin-LGR5 complex functions as a Wnt pathway regulator, probably forming a positive feedback loop, magnifying the Wnt pathway (Figure 2C and D).

"Blue ribbon visualization" is an in vivo lineage-tracing technique that uses the $L a c Z$ reporter gene under the activity of a promoter, allowing the identification of a cell of interest and its tracing in potential progeny. This method has revealed 
A

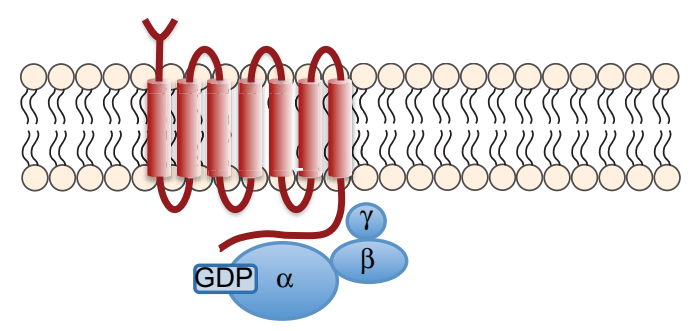

B
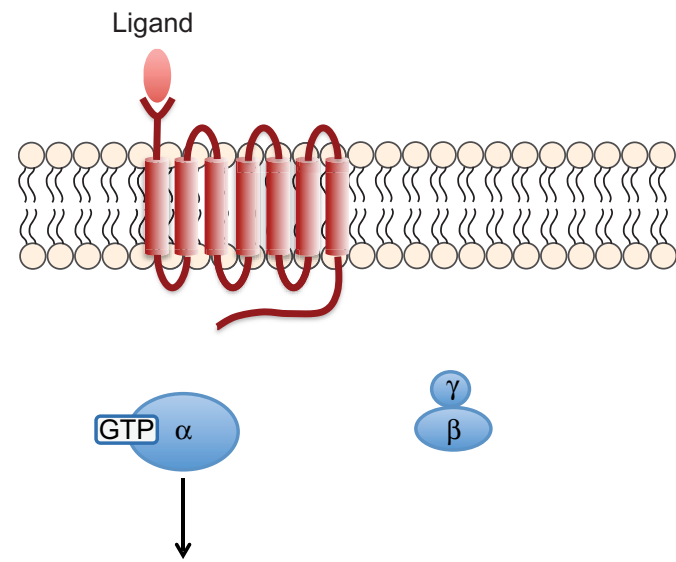

Activation/inhibition of various effectors
C

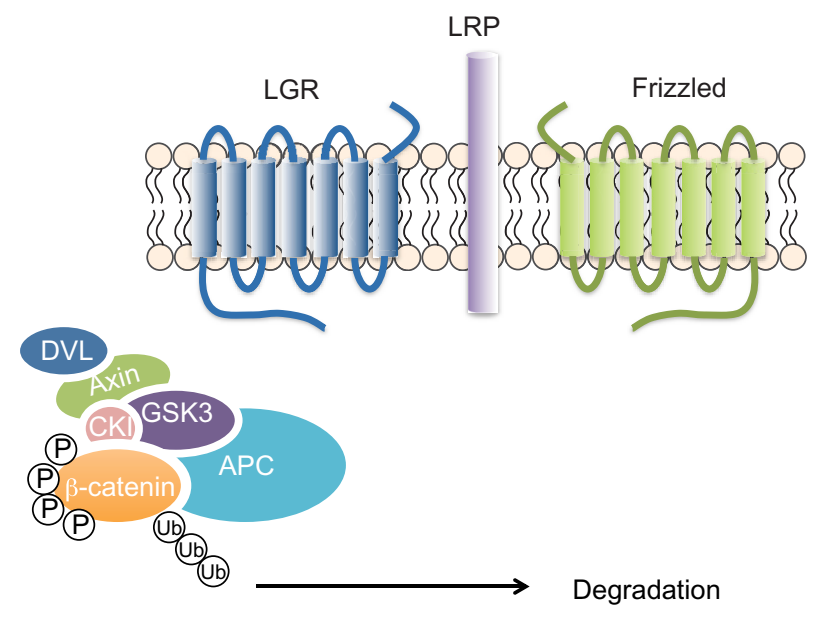

D

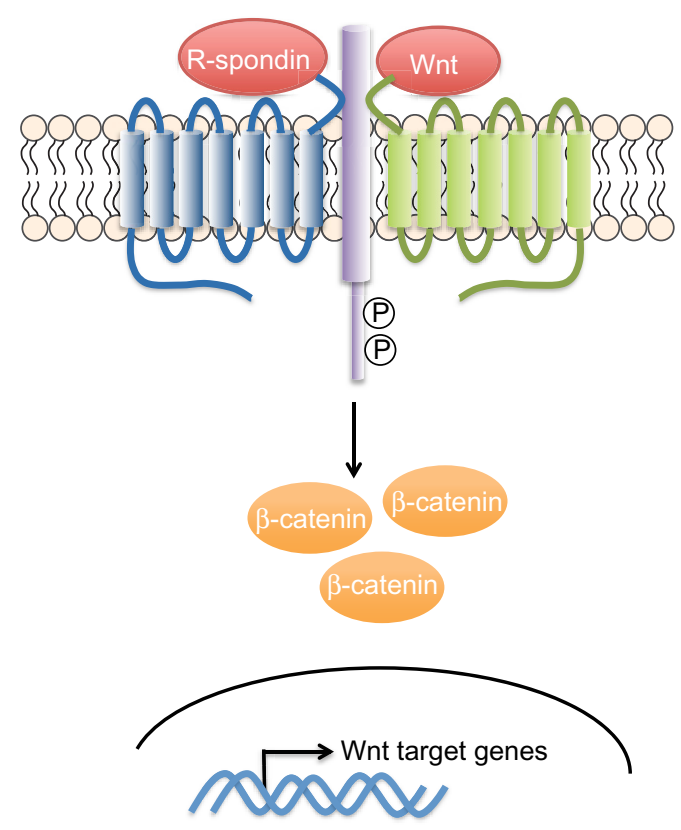

Figure 2 The G-protein coupled receptors signaling pathway.

Notes: (A) The seven transmembrane domains of the GPCRs activate a panel of heterotrimeric G-proteins that differ at the level of their $\alpha$-subunits. (B) Upon ligand stimulation of the GPCR, the $\alpha$-subunit separates from the $\beta$ - and $\gamma$-subunits and activates or inhibits different cytoplasmic enzymes. (C and D) In contrast to classical GPCRs, LGR4-6 do not activate heterotrimeric G-proteins to transduce the signal. Rather, upon R-spondin binding, they recruit the LRP-frizzled receptor complex, which binds to Wnt ligands, leading to the phosphorylation of LRP. The receptor complex then recruits the axin complex. $\beta$-catenin is no longer marked by phosphorylation for degradation, leading to its stabilization and accumulation and, ultimately, translocation into the nucleus. Based on Schuijers and Clevers with the permission of John Wiley and Sons. Adult mammalian stem cells: the role of Wnt, Lgr5 and R-spondins. EMBO J. 20I2;3I(I2):2685-2696.91

Abbreviations: APC, adenomatous polyposis coli; CKI, casein kinase I; GDP, guanosine diphosphate; GPCR, G-protein-coupled receptor; GSK3, glycogen synthase kinase 3; GTP, guanosine triphosphate; LGR, leucine-rich repeat-containing GPCR; LRP, lipoprotein receptor-related protein; P, phosphate group; DVL, Dishevelled; Ub, Ubiquitin.

that LGR5 is a stem cell marker in various organs including the intestinal mucosa, ${ }^{21}$ colon, ${ }^{22}$ stomach,${ }^{23}$ hair follicle, ${ }^{24}$ kidney ${ }^{25}$ and mammary gland. ${ }^{26}$ In the small intestine, LGR5 ${ }^{+v e}$ cells at the bottom of crypts can be the cell of origin for all cell types in the epithelium. As such, a single LGR5 ${ }^{\text {+ve }}$ cell can generate a "mini-gut"-like organoid culture in vitro, recapitulating the crypt structure. ${ }^{27}$ Intriguingly, LGR5 ${ }^{\text {+ve }}$ cells initially produce Paneth cells, which in turn provide niche factors such as Wnt3 for the LGR $5^{+v e}$ stem cell in the intestinal stem cell system. ${ }^{28}$ 

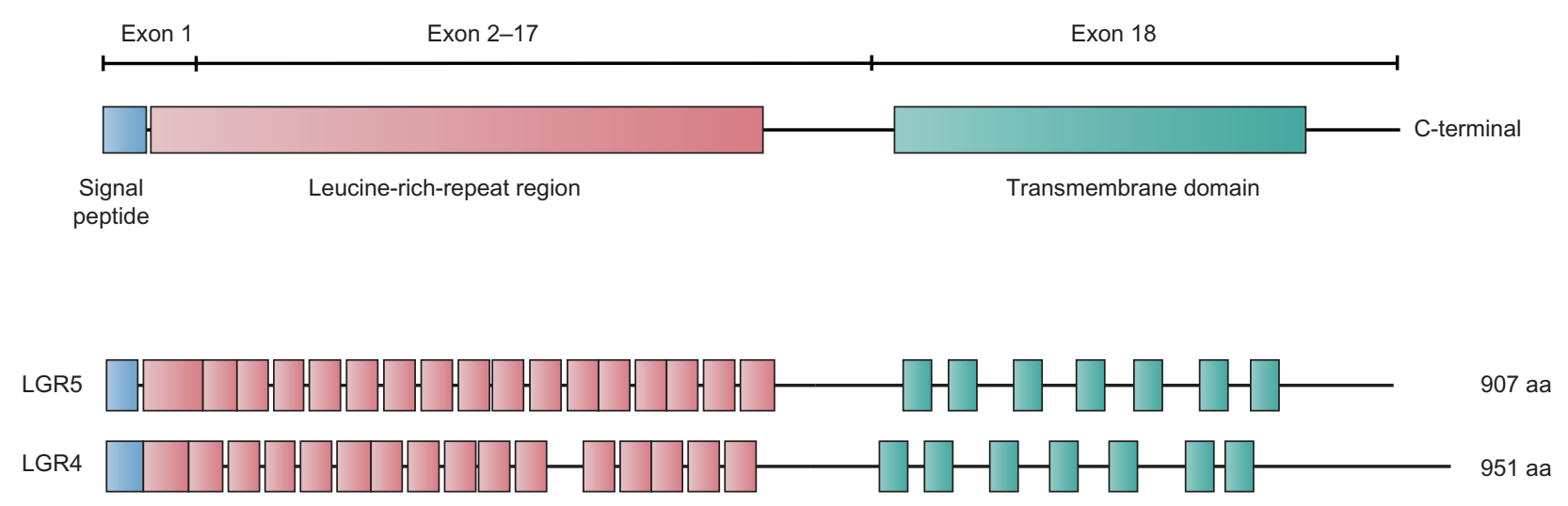

Figure 3 Scheme depicting the structures of the LGR4 and LGR5 proteins.

Abbreviation: LGR, leucine-rich repeat-containing G-protein-coupled receptor.

In LGR4 knockout mice it was shown that LGR4 is critical for the development of various organs, including the male reproductive tract, ${ }^{29}$ kidney, ${ }^{30}$ eyelid, ${ }^{31}$ erythropoiesis, ${ }^{32}$ hair placode, ${ }^{33}$ gallbladder and cystic duct, ${ }^{34}$ and bones ${ }^{35}$ Notably, it has recently been reported that a c. $376 \mathrm{C}<\mathrm{T}$ nonsense mutation of human LGR4 results in termination at position 126. This mutation, leading to the complete loss of function of LGR4, has significant correlation with risks for osteoporosis, assessed by low bone mineral density, reduced testosterone levels, skin squamous cell carcinoma (SCC), and gallbladder/biliary tract cancer. ${ }^{36}$ These results, identified by whole-genome sequencing in a large population, clearly show striking parallels with phenotypes observed in LGR4 knockout mice, and imply putative functions of LGR4 as a tumor suppressor gene.

Consistent with a potential role of LGR in morphogenesis, LGR5 knockout mice show 100\% neonatal lethality with ankyloglossia, an abnormal craniofacial morphogenesis characterized by the fusion of the tongue to the floor of the oral cavity. ${ }^{37}$ Since LGR4 was shown to be able to compensate LGR5 function in intestinal crypts, the process of the tongue's development seems to be solely dependent on LGR5.

In the small intestine, LGR4 is expressed in all cell types within crypts, whereas LGR5 is restricted to crypt base columnar intestinal stem cells. It has been demonstrated that LGR4 is required for the "mini-gut" organoid culture in vitro, which is derived from LGR $5^{\text {+ve }}$ stem cells. Double knockout of both LGR4 and LGR5 completely abolished not only generation of the organoid, but also maintenance of crypts in vivo. ${ }^{19}$ The abolishment of organoid formation by the LGR $4 / 5$ deletion could be rescued by Wnt activation. Using a Wnt reporter system in HEK293T (transfection of human embryonic kidney cell line. 293T) cells, LGR5 could compensate for the loss of Wnt signal activities caused by LGR4 knockdown. These findings suggest that LGR4 and LGR5 share the role of modulating the Wnt signaling pathway through R-spondin binding. Concordantly, immunoprecipitation assays demonstrated that all $\mathrm{R}$-spondins (1-4) bind to LGR4 $-6,{ }^{19}$ and the contact residues of LGR4-6 at the binding sites of the R-spondins are strictly conserved. ${ }^{20}$

\section{Suggested role of LGR5 and LGR4 in CSCs}

Recent advances using genetically modified mouse models have dramatically deepened our understanding of the adult tissue stem cell system harboring plasticity.

Indeed, the in vivo lineage tracing technique using the $\mathrm{LacZ}$ gene as a reporter revealed the plasticity in the early process of differentiation into Paneth cells, which can restore the LGR $5^{+v e}$ stem cell phenotype when regenerative machinery is switched on as a response to injury. ${ }^{38}$ Significantly, this model provides explanations for the two biggest mysteries debated for a long time in the intestinal stem cell system field: ie, the controversy between the models of the rapidly cycling LGR $5^{\text {tve }}$ crypt base columnar stem cells versus the BMI $1^{\text {+ve }}$ quiescent stem cells located at the base of the crypt ${ }^{39}$ and the issue of why LGR $5^{\text {+ve }}$ stem cells in crypts are dispensable when LGR5 stem cells are sources for all types of cells found in the crypt. ${ }^{40}$ The model proposes that the LGR5 positive stem cell-derived quiescent Paneth precursor cells at the base of the crypt, which are usually committed to becoming long-lived Paneth cells, can be a reservoir pool to restore the LGR5 stem cell population when needed in response to tissue damage. ${ }^{38}$ Hence, these striking findings clearly impact the fields of both stem cell and CSC biology. A list of cancer entities in which LGR4 and LGR5 have been studied is summarized in Table 1.

\section{LGR5 in hepatocellular carcinoma}

A decade ago, one of the pioneering studies on LGR5 in cancer reported the overexpression of LGR5 in hepatocellular 
Table I Summary of the involvement of LGR4 and LGR5 in different tumor entities

\begin{tabular}{|c|c|c|}
\hline Tumor type & Molecular status & Studies \\
\hline \multicolumn{3}{|l|}{ LGR4 } \\
\hline $\begin{array}{l}\text { Skin, squamous } \\
\text { cell carcinoma }\end{array}$ & Mutation, loss-of-function & $\begin{array}{l}\text { Styrkarsdottir } \\
\text { et } \mathrm{al}^{36}\end{array}$ \\
\hline $\begin{array}{l}\text { Gallbladder/biliary } \\
\text { tract cancer }\end{array}$ & Mutation, loss-of-function & $\begin{array}{l}\text { Styrkarsdottir } \\
\text { et } \mathrm{al}^{36}\end{array}$ \\
\hline \multicolumn{3}{|l|}{ LGR5 } \\
\hline $\begin{array}{l}\text { Hepatocellular } \\
\text { carcinoma }\end{array}$ & Overexpression & Yamamoto et $\mathrm{al}^{41}$ \\
\hline Colon cancer & Overexpression & $\begin{array}{l}\text { Walker et al, }{ }^{48} \\
\text { Aguilera et al, }{ }^{49} \\
\text { Al-Kharusi et al, }{ }^{50} \\
\text { de Sousa et al, }{ }^{51} \\
\text { Sancho et al, }{ }^{52} \text { and } \\
\text { van der Flier et al }{ }^{53}\end{array}$ \\
\hline Basal cell carcinoma & Overexpression & Tanese et $\mathrm{al}^{54}$ \\
\hline Breast cancer & $\begin{array}{l}\text { High expression in spheroid } \\
\text { cultures and metastasis- } \\
\text { inducing potential }\end{array}$ & Oskarsson et $\mathrm{al}^{63}$ \\
\hline Glioblastoma & $\begin{array}{l}\text { High expression } \\
\text { in spheroid cultures }\end{array}$ & Nakata et $\mathrm{al}^{64}$ \\
\hline Sarcoma & Gene locus amplification & Barretina et $\mathrm{al}^{73}$ \\
\hline Gastric cancer & $\begin{array}{l}\text { Correlation between } \\
\text { expression and tumor } \\
\text { differentiation level }\end{array}$ & $\begin{array}{l}\text { Bauer et } \mathrm{al}^{76} \\
\text { Wu et al, }{ }^{77} \text { and } \\
\text { Voon et } \mathrm{al}^{78}\end{array}$ \\
\hline $\begin{array}{l}\text { Lung } \\
\text { adenocarcinoma }\end{array}$ & $\begin{array}{l}\text { Correlation between } \\
\text { expression and tumor stage }\end{array}$ & Ryuge et $\mathrm{al}^{79}$ \\
\hline
\end{tabular}

Abbreviation: LGR, leucine-rich repeat-containing G-protein-coupled receptor.

carcinomas, pointing out the correlation with $\beta$-catenin mutations causing aberrant activation of the canonical Wnt pathway. ${ }^{41}$ Recently, it was shown that in regenerative liver tissue induced by chemical injury, LGR5 marks liver stem cells, which can generate hepatocellular and cholangiocyte lineages ${ }^{42}$ However, the role of LGR5 in hepatocellular carcinoma stem cells still remains to be elucidated.

\section{LGR5 in colon carcinoma}

Given the specific expression of LGR5 in the stem cell compartment of the intestinal crypts, LGR5 is being intensively investigated in the field of colorectal cancer.

Many studies have defined LGR5 as a new stem cell marker, denoting the cell of origin for intestinal tumors similarly to prominin-1, also known as CD133.43-47 Indeed, several studies have demonstrated that both markers highlight the compartment of adult stem cells. ${ }^{43,44}$ However, it was shown that lineage tracing of prominin-1 ${ }^{+ \text {ve }}$ cells using its promoter failed to mark restricted expression in intestinal stem cells ${ }^{45}$ suggesting that differences in the constructs in genetic mouse models can affect the results of such cell fate tracking. Moreover, the Wnt pathway has also been suggested to regulate prominin- 1 expression, ${ }^{46}$ concordantly with its central regulation for LGR5 expression in intestinal crypts.

Another study highlighted the capability of LGR 5 to mark the long-lived intestinal stem cells and thereby the potential cells of origin. Indeed, specific deletion of the adenomatous polyposis coli gene, known to initiate intestinal cancer by Wnt-pathway-activating mutations, rapidly induced intestinal adenomas in LGR5 ${ }^{\text {tve }}$ stem cells, but could not maintain adenomas when introduced to transit amplifying cells. ${ }^{47}$

In colon cancer cells, LGR5 could function as a negative regulator of the Wnt pathway, which is contradictory to findings in intestinal stem cells, suggesting its cellular context-dependent functions. ${ }^{48}$ Indeed, several regulatory mechanisms for LGR5 expression have been identified in various cellular contexts. ${ }^{49-53}$ ASCL2 (Achaete-scute complex homolog 2) is a basic helix-loop-helix transcription factor, which binds to the LGR5 promoter and is indispensible for maintenance of intestinal stem cells, exhibiting a restricted expression pattern in the compartment. ${ }^{53}$ Inhibition of a protooncogene c-Jun, a component of the activator protein-1 (AP1) signaling pathway, decreases $L G R 5$ expression in intestinal stem cells, together with Wnt pathway target genes. ${ }^{52} \mathrm{c}$-Jun protein binds to the intronic region of the $L G R 5$ gene locus and transactivates $L G R 5$ expression upon phosphorylationmediated activation of AP1 signaling. ${ }^{49}$ This suggests the regulation of $L G R 5$ expression due to the crosstalk of the $\mathrm{Wnt}$ and AP1 signaling pathways in intestinal stem cells.

In adenoma cells, a Wnt pathway enhancer, prostaglandin E2, increases LGR5 protein but not mRNA (messenger ribonucleic acid) levels independently of $\beta$-catenin, indicating post-translational regulation of LGR5 protein expression and conditional regulation of LGR5. ${ }^{50}$ In addition, it was shown that promoter methylation can cause repression of LGR5 expression in some colon cancer cells. ${ }^{51}$

\section{LGRs in hair follicles and skin cancer}

Hair follicle stem cells are also marked with restricted expression of LGR5. Using the lineage tracing system, it was shown that LGR5 $5^{\text {+ve }}$ cells in the bulge region of hair follicles represent the stem cell population, which could generate all cell lineages of hair follicles in vivo (but not of interfollicular epidermis and sebaceous glands) and efficiently generate hair follicles in transplanted nude mice. ${ }^{24} \mathrm{LGR} 5^{\text {+ve }}$ cells reside in the outer root sheath in the anagen phase, and actively cycle and migrate to generate progenies consisting of new hair follicles. Interestingly, expression profiles of the LGR $5^{\text {tve }}$ hair follicle stem cells revealed the involvement of the sonic hedgehog signaling pathway, which was shown to regulate LGR5 in basal 
cell carcinoma (BCC) ${ }^{54}$ In hair follicle progenitor cells, the Limhomeodomain transcription factor Lhx2 (Lim homeobox 2) binds to the LGR5 promoter, shown by chromatin immunoprecipitation analysis, and negatively regulates its expression. ${ }^{55}$

In an experiment combining the LGR5-lineage tracing system with a mouse model mimicking BCC with induced aberrant activation of sonic hedgehog signaling, it was shown that LGR5-traced hair follicle-derived cells are recruited in the early stages of BCC-like carcinogenesis in the interfollicle epidermis upon wounding. ${ }^{56}$ Another group combined LGR5lineage tracing and a skin SCC mouse model induced by E6/E7 oncogenes from human papilloma virus 16, driven by the K14 promoter. The animals developed SCC-like lesions, comprising $\mathrm{K} 15^{\text {tve }}$ abnormal cells, which were traced as progenies of LGR $5^{+v e}$ cells. ${ }^{57}$ Thus, these cells are suggested to be the cells of origin for the experimental SCC model. Intriguingly, an integrated analysis of germline polymorphism and expression profiling using a backcross of skin cancer resistant and susceptible mouse strains identified LGR5 as a potential master regulator gene of the hair follicle. ${ }^{58}$

\section{LGR4 and LGR5 in the mammary gland and breast cancer}

One of the initial reports using LGR5-lineage tracing in the normal mammary gland showed that $\mathrm{LGR} 5^{\text {+ve }}$ cells represent lineage-committed mammary epithelial cells, which give rise only to myoepithelial cells, suggesting their limited potential. ${ }^{59}$ It was also shown that $\mathrm{LGR} 5^{\text {+ve }}$ cells represent lineage-committed epithelial cells in physiological conditions, although LGR5 ${ }^{\text {+ve }}$ cells could be identified within the previously established $\mathrm{CD} 45^{-} \mathrm{CD} 24^{\mathrm{mid}} \mathrm{CD} 49 \mathrm{f}^{\text {high }}$ mammary gland stem cell fraction. ${ }^{60}$ Under the stressed and regenerative conditions of the transplantation assay, LGR $5^{\text {+ve }}$ cells showed slightly enhanced capability to reconstitute mammary glands. However, the ability to reconstitute was also observed in LGR5 ${ }^{-v e}$ cells. Taken together, these results suggest LGR5 is expressed in lineage-committed cells that lack stem cell properties.

In contrast, more recently, it has been demonstrated that LGR5 clearly marks and characterizes the mammary gland stem cell fraction. ${ }^{26}$ LGR5 expression was detected within selected populations in the basal cells of mammary glands. LGR5 $5^{\text {ve }}$ basal cells exhibit higher activity to reconstitute new mammary glands in vivo. ${ }^{26}$ These cells comprise a rare population within the $\mathrm{Lin}^{-} \mathrm{CD} 24^{+} \mathrm{CD} 49 \mathrm{f}^{\text {high }}$ basal cell fraction that includes mammary stem cells. ${ }^{61,62}$ LGR5 enriches the mammary gland stem cells, which are capable of reconstitution from a single cell in serial transplantation assays to a much higher extent (one cell in four) than the other $\mathrm{Lin}^{-} \mathrm{CD} 24^{+} \mathrm{CD} 49 \mathrm{f}^{\text {high }}$ basal cells. Moreover, the report demonstrated that a depletion assay of LGR5expressing cells using the LGR5-DTR (diphtheria toxin receptor) mouse strain resulted in a significant decrease of the reconstruction potential of mammary glands, unlike in the case of intestinal stem cells. ${ }^{40}$ These findings indicate that LGR $5^{+v e}$ cells represent indispensible mammary gland stem cells. Turning to breast cancer, it has been reported that an extracellular matrix component, tenascin, is a key regulator of lung metastasis of breast cancer. ${ }^{63}$ In breast cancer cells, the expression level of tenascin regulates LGR5 expression, together with Msi1 (Musashi-1), a neural stem cell marker gene. Tenascin regulates spheroid formation derived from breast cancer cells. In spheroid cultures derived from breast cancer, LGR5 is more highly expressed than in adherent culture, in line with the observations in colorectal and glioblastoma spheroid cultures. ${ }^{64}$ It was shown that LGR5 knockdown reduces lung metastases, suggesting a key role of LGR5 in CSC regulation, including metastasis-initiating potentials in breast cancer.

A recent study showed that LGR4 functions in mammary gland development and mammary stem cells by activating Sox2 (sex determining region Y-box 2) via the Wnt/ $\beta$-catenin/Lef1 (lymphoid enhancer-binding factor 1) signaling pathway. ${ }^{65}$

\section{LGR5 in glioblastoma stem cells}

In the 1990s, the localization of the expression of LGR5 was studied by in situ hybridization in the embryonic central nervous system and other tissues. ${ }^{66}$ The authors reported that LGR5 is expressed in selected regions in the embryonic central nervous system, the developing face, the intervertebral disc anlagen, and the limb bud, at the active morphogenesis stage. In contrast, in adult mouse brain, LGR5 expression was not detected, except in the olfactory bulb in the central nervous system. These findings suggest that LGR5 is expressed in primitive neural cells during development only.

Recent findings showed that LGR $5^{\text {+ve }}$ cells isolated from cochlear sensory epithelium are capable of expansion, forming neurospheres, and could be induced to form differentiated hair sensory cells, suggesting that LGR5 $5^{\text {+ve }}$ cells are functional progenitors of hair cells.

Recently, two groups reported findings by lineage tracing in a particular kind of neural cell: the inner ear hair cell precursors/progenitors in cochlea tissue. ${ }^{67,68}$

Glioblastoma is the most frequent and malignant type of brain cancer. One of the pioneering studies on solid CSC research reported that CD133 marks glioblastoma stem cells. CD133 is a stem cell marker for hematopoietic and central 
nervous system and has been applied for the identification of CSCs in various types of malignancies, including colon cancer. ${ }^{69}$ In parallel with colon CSCs, it has been reported that LGR5 is highly expressed in the CSC fraction of glioblastoma, and upon induced differentiation, the expression of LGR 5 is decreased. ${ }^{64,70}$ Using meta-analysis of expression data, it has been shown that LGR5 is significantly more highly expressed in CD133-sorted cells from glioblastoma compared with the counterpart CD133-ve population. ${ }^{64}$ In line with these observations, inhibition of LGR5 gene expression in glioblastoma stem-like cells causes cell death. In parallel to apoptosis induction, several stemness-related genes including Wnt or sonic-hedgehog pathway and cell cycle regulators such as L1CAM (human L1 cell adhesion molecule), FZD3 (frizzled homolog 3), PTCHD1 (patched domain containing 1), and CDKN1B (cyclin-dependent kinase inhibitor 1B) were significantly deregulated. ${ }^{64}$ These findings imply that LGR5-mediated regulation of Wnt signaling is required for expansion of the glioblastoma stem cell population. Interestingly, inhibition of LGR5 causes a decrease in PFKFB4 (6-phosphofructo-2-kinase/fructose-2,6-biphosphatase 4) expression, which was recently identified as an indispensable gene for the glioblastoma stem-like cell survival. ${ }^{71}$

In glioma, it was reported that the locus of $12 \mathrm{q} 21$ on which the LGR5 gene resides is frequently amplified. However, correlation of the mRNA expression of LGR 5 with the genomic status could not be confirmed, possibly due to the small number of cases assessed by quantitative real-time polymerase chain reaction $(n=5){ }^{72}$

\section{Additional tumor entities in which LGR5 involvement is suggested}

A genome-wide study on soft tissue sarcoma samples identified the LGR5 gene locus as frequently amplified. ${ }^{73}$ Another report on clinical sarcoma samples described a novel splice variant of LGR5 identified in soft tissue sarcoma, of which lower expression was shown to be associated with worse overall survival. ${ }^{74}$ It has recently been reported that LGR5 is enriched in CD133 ${ }^{\text {ve }}$ cells sorted from a Ewing's sarcoma cell line. ${ }^{75}$ In Ewing's sarcoma patients, LGR5 is highly expressed in more aggressive cases with worse outcome.

In gastric cancer, it has been reported that post-therapeutic tissue expresses significantly higher levels of LGR5, NOTCH2, and POU5F1 (POU class 5 homeobox 1) mRNA, suggesting that $\mathrm{LGR}^{+\mathrm{ve}}$ gastric cancer cells could be therapy resistant. ${ }^{76}$ Upon analysis of a large cohort of 160 gastric adenocarcinoma samples and 99 normal mucosa samples, LGR5 could be detected at the bottom of the normal gastric gland unit along with the putative CSC markers CD26,
CD44, ALDH1 (aldehyde dehydrogenase 1), and CD133, but was differentially expressed in gastric cancer tissues. ${ }^{77}$ Low-differentiated gastric cancer showed lower expression of LGR5, in contrast to findings in glioblastoma. A recent report described that transforming growth factor beta-induced epithelial-mesenchymal transition in runt-related transcription factor 3 (Runx 3$)^{-/} \mathrm{p} 53^{-/-}$murine gastric epithelial cells accompanied with epidermal growth factor receptor/RAS (rat sarcoma viral oncogene) activation resulted in LGR5 induction, together with enhanced spheroid and colony formation activities. ${ }^{78}$ Forced expression of KRAS (Kirsten rat sarcoma viral oncogene homolog) was also shown to be sufficient to induce LGR5 and sphere-forming activity in the murine gastric epithelial cells.

Furthermore, in lung adenocarcinoma clinical samples, LGR5 expression was shown to correlate with higher disease stage, larger tumor size, and shorter overall survival rate. ${ }^{79}$ These findings imply the involvement of LGR5 in the pathogenesis of these tumor entities. Nonetheless, further analysis of its molecular function and usefulness as a CSC marker is required.

\section{Potential clinical implications}

The identification of the LGR5 $5^{\text {+ve }}$ bona fide intestinal stem cell population enabled the establishment of the expression profile signature specific for the compartment purified from the mouse intestine. This allowed the stratification of clinical colorectal cancer samples. ${ }^{80}$ Importantly, the LGR5 intestinal stem cell signature was able to predict disease relapse in colorectal cancer patients. In the study, another Wnt target gene, the receptor tyrosine kinase EphB2 (ephrin type-B receptor 2), was used to sort intestinal cells as it is decreasingly expressed from the bottom of crypts toward the upper differentiated area. The EphB2-based enrichment of the colorectal CSCs clearly showed high expression of LGR5 in the fraction. The spheroid culture system maintained in serum-free medium supplemented with growth factors established from colorectal cancer specimens or cell lines has been shown to be highly tumorigenic and to highly express LGR5 ${ }^{81,82}$ However, technical difficulties have impeded the isolation of LGR5 ${ }^{\text {tve }}$ cells from clinical cancer samples. Recently, originally generated antibodies were applied for the enrichment of the CSC fraction in colorectal cancer. ${ }^{83}$ Moreover, it was shown that overexpression of $L G R 5$ enhanced clonogenicity, whereas knockdown of LGR5 attenuated it, indicating the direct control of this colorectal CSC property by LGR5. Although it has been suggested that the R-spondin-LGR5 autocrine loop potentially regulates the $\mathrm{LGR}^{\text {+ve }}$ colorectal CSCs, further elucidation of the nature 
of LGR5 ${ }^{\text {+ve }}$ colorectal cancer cells is needed and may reveal novel therapeutic targets.

Interestingly, it was recently reported that the tissue microarray based immunostaining of a large cohort of nearly 300 glioma cases reveals a correlation of LGR5 expression with tumor malignancy. In addition, LGR5 was described as being associated with glioblastoma prognosis. ${ }^{64}$

\section{Potential application of LGR5 as a therapeutic target}

Given that CSCs often utilize developmental signaling pathways, intensive efforts are being undertaken to develop Wnt signaling inhibitors aiming at selective therapeutics targeting CSCs. ${ }^{84,85}$ However, the complexity of Wnt signaling has rendered this a challenging task; the Wnt pathway comprising 19 Wnt ligands, 10 frizzled transmembrane receptors, LRP regulatory co-receptors, numerous modulating molecules involved in the downstream signaling cascades, including DVL, axin, and adenomatous polyposis coli, and transcription factor complex components such as CBP (CREB binding protein) and p300. ${ }^{86}$ These components are currently being investigated preclinically and, in part, clinically, as therapeutic targets. ${ }^{84,85}$ Targeting LGR5 may offer a further strategy to block the amplification system of the Wnt signaling pathway for the stem cell compartment. The molecular structure of LGR5 offers potential options for therapeutic intervention. In fact, the majority of therapeutic drug targets currently in clinical use are actually GPCRs. ${ }^{87}$ The recently unveiled binding mode of LGR5 and R-spondin may give hints to aid the development of small molecule blockers or antagonizing antibodies to attack the specific Wnt-enhancing machinery for the stem cell compartment. ${ }^{88,89}$ Indeed, the study demonstrated the potential of antibody-based modulation of the Wnt-enhancing function of R-spondin and LGR 5 complex. ${ }^{20}$ In addition, possibilities of LGR5 targeted antibody-based therapy mediated by complement-dependent cytotoxicity in vitro, and an antitumor effect in a xenograft model has been demonstrated..$^{90}$

\section{Acknowledgments}

We thank Dr Josephine Bageritz and Prof Dr Peter Lichter for their critical reading and their helpful suggestions.

\section{Disclosure}

The authors declare no conflicts of interest in this work.

\section{References}

1. Quintana E, Shackleton M, Sabel MS, Fullen DR, Johnson TM, Morrison SJ. Efficient tumour formation by single human melanoma cells. Nature. 2008;456(7222):593-598.
2. Roesch A, Fukunaga-Kalabis M, Schmidt EC, et al. A temporarily distinct subpopulation of slow-cycling melanoma cells is required for continuous tumor growth. Cell. 2010;141(4):583-594.

3. Reya T, Morrison SJ, Clarke MF, Weissman IL. Stem cells, cancer, and cancer stem cells. Nature. 2001;414(6859):105-111.

4. Laks DR, Visnyei K, Kornblum HI. Brain tumor stem cells as therapeutic targets in models of glioma. Yonsei Med J. 2010;51(5): 633-640.

5. Anderson AR, Weaver AM, Cummings PT, Quaranta V. Tumor morphology and phenotypic evolution driven by selective pressure from the microenvironment. Cell. 2006;127(5):905-915.

6. Greaves M, Maley CC. Clonal evolution in cancer. Nature. 2012; 481(7381):306-313.

7. Lapidot T, Sirard C, Vormoor J, et al. A cell initiating human acute myeloid leukaemia after transplantation into SCID mice. Nature. 1994;367(6464):645-648.

8. Huntly BJ, Gilliland DG. Leukaemia stem cells and the evolution of cancer-stem-cell research. Nat Rev Cancer. 2005;5(4):311-321.

9. Bonnet D, Dick JE. Human acute myeloid leukemia is organized as a hierarchy that originates from a primitive hematopoietic cell. Nat Med. 1997;3(7):730-737.

10. Wang JC, Lapidot T, Cashman JD, et al. High level engraftment of NOD/SCID mice by primitive normal and leukemic hematopoietic cells from patients with chronic myeloid leukemia in chronic phase. Blood. 1998;91(7):2406-2414.

11. Sirard C, Lapidot T, Vormoor J, et al. Normal and leukemic SCIDrepopulating cells (SRC) coexist in the bone marrow and peripheral blood from CML patients in chronic phase, whereas leukemic SRC are detected in blast crisis. Blood. 1996;87(4):1539-1548.

12. Huff CA, Matsui W. Multiple myeloma cancer stem cells. JClin Oncol. 2008;26(17):2895-2900.

13. Jones RJ, Gocke CD, Kasamon YL, et al. Circulating clonotypic B cells in classic Hodgkin lymphoma. Blood. 2009;113(23):5920-5926.

14. Visvader JE, Lindeman GJ. Cancer stem cells in solid tumours: accumulating evidence and unresolved questions. Nat Rev Cancer. 2008;8(10):755-768.

15. Klonisch T, Wiechec E, Hombach-Klonisch S, et al. Cancer stem cell markers in common cancers - therapeutic implications. Trends $\mathrm{Mol}$ Med. 2008;14(10):450-460.

16. Kim J, Orkin S. Embryonic stem cell-specific signatures in cancer: insights into genomic regulatory networks and implications for medicine. Genome Med. 2011;3(11):75.

17. Dorsam RT, Gutkind JS. G-protein-coupled receptors and cancer. Nat Rev Cancer. 2007;7(2):79-94.

18. Hsu SY, Liang SG, Hsueh AJ. Characterization of two LGR genes homologous to gonadotropin and thyrotropin receptors with extracellular leucine-rich repeats and a $\mathrm{G}$ protein-coupled, seven-transmembrane region. Mol Endocrinol. 1998;12(12):1830-1845.

19. de Lau W, Barker N, Low TY, et al. LGR5 homologues associate with Wnt receptors and mediate R-spondin signalling. Nature. 2011;476(7360):293-297.

20. Peng WC, de Lau W, Forneris F, et al. Structure of stem cell growth factor R-spondin 1 in complex with the ectodomain of its receptor LGR5. Cell Rep. 2013;3(6):1885-1892.

21. Barker N, van Es JH, Kuipers J, et al. Identification of stem cells in small intestine and colon by marker gene LGR5. Nature. 2007;449(7165):1003-1007.

22. Baker M. Stem cells by any other name. Nature. 2007;449(7161): 389.

23. Barker N, Huch M, Kujala P, et al. LGR5(+ve) stem cells drive selfrenewal in the stomach and build long-lived gastric units in vitro. Cell Stem Cell. 2010;6(1):25-36.

24. Jaks V, Barker N, Kasper M, et al. LGR5 marks cycling, yet long-lived, hair follicle stem cells. Nat Genet. 2008;40(11):1291-1299.

25. Barker N, Rookmaaker MB, Kujala P, et al. LGR5(+ve) stem/progenitor cells contribute to nephron formation during kidney development. Cell Rep. 2012;2(3):540-552. 
26. Plaks V, Brenot A, Lawson DA, et al. LGR5-expressing cells are sufficient and necessary for postnatal mammary gland organogenesis. Cell Rep. 2013;3(1):70-78.

27. Sato T, Vries RG, Snippert HJ, et al. Single LGR5 stem cells build crypt-villus structures in vitro without a mesenchymal niche. Nature. 2009;459(7244):262-265.

28. Sato T, van Es JH, Snippert HJ, et al. Paneth cells constitute the niche for LGR5 stem cells in intestinal crypts. Nature. 2011;469(7330): 415-418.

29. Mendive F, Laurent P, Van Schoore G, Skarnes W, Pochet R, Vassart G. Defective postnatal development of the male reproductive tract in LGR4 knockout mice. Dev Biol. 2006;290(2):421-434.

30. Kato S, Matsubara M, Matsuo T, et al. Leucine-rich repeat-containing G protein-coupled receptor-4 (LGR4, Gpr48) is essential for renal development in mice. Nephron Exp Nephrol. 2006;104(2):e63-e75.

31. Kato S, Mohri Y, Matsuo T, et al. Eye-open at birth phenotype with reduced keratinocyte motility in LGR4 null mice. FEBS Lett. 2007;581(24):4685-4690.

32. Song H, Luo J, Luo W, et al. Inactivation of G-protein-coupled receptor 48 (Gpr48/LGR4) impairs definitive erythropoiesis at midgestation through down-regulation of the ATF4 signaling pathway. J Biol Chem. 2008;283(52):36687-36697.

33. Mohri Y, Kato S, Umezawa A, Okuyama R, Nishimori K. Impaired hair placode formation with reduced expression of hair follicle-related genes in mice lacking LGR4. Dev Dyn. 2008;237(8):2235-2242.

34. Yamashita R, Takegawa Y, Sakumoto M, et al. Defective development of the gall bladder and cystic duct in LGR4- hypomorphic mice. Dev Dyn. 2009;238(4):993-1000.

35. Luo J, Zhou W, Zhou X, et al. Regulation of bone formation and remodeling by G-protein-coupled receptor 48. Development. 2009;136(16): 2747-2756.

36. Styrkarsdottir U, Thorleifsson G, Sulem P, et al. Nonsense mutation in the LGR4 gene is associated with several human diseases and other traits. Nature. 2013;497(7450):517-520.

37. Morita H, Mazerbourg S, Bouley DM, et al. Neonatal lethality of LGR5 null mice is associated with ankyloglossia and gastrointestinal distension. Mol Cell Biol. 2004;24(22):9736-9743.

38. Buczacki SJ, Zecchini HI, Nicholson AM, et al. Intestinal labelretaining cells are secretory precursors expressing LGR5. Nature. 2013;495(7439):65-69.

39. Sangiorgi E, Capecchi MR. Bmi1 is expressed in vivo in intestinal stem cells. Nat Genet. 2008;40(7):915-920.

40. Tian H, Biehs B, Warming S, et al. A reserve stem cell population in small intestine renders LGR5-positive cells dispensable. Nature. 2011;478(7368):255-259.

41. Yamamoto Y, Sakamoto M, Fujii G, et al. Overexpression of orphan G-protein-coupled receptor, Gpr49, in human hepatocellular carcinomas with beta-catenin mutations. Hepatology. 2003;37(3):528-533.

42. Huch M, Dorrell C, Boj SF, et al. In vitro expansion of single LGR5+ liver stem cells induced by Wnt-driven regeneration. Nature. 2013;494(7436):247-250.

43. Zhu L, Gibson P, Currle DS, et al. Prominin 1 marks intestinal stem cells that are susceptible to neoplastic transformation. Nature. 2009;457(7229):603-607.

44. Snippert HJ, van Es JH, van den Born M, et al. Prominin-1/CD133 marks stem cells and early progenitors in mouse small intestine. Gastroenterology. 2009;136(7):2187-2194. e1.

45. Shmelkov SV, Butler JM, Hooper AT, et al. CD133 expression is not restricted to stem cells, and both CD133+ and CD133- metastatic colon cancer cells initiate tumors. J Clin Invest. 2008;118(6):2111-2120.

46. Mizrak D, Brittan M, Alison M. CD133: molecule of the moment. J Pathol. 2008;214(1):3-9.

47. Barker N, Ridgway RA, van Es JH, et al. Crypt stem cells as the cellsof-origin of intestinal cancer. Nature. 2009;457(7229):608-611.

48. Walker F, Zhang HH, Odorizzi A, Burgess AW. LGR5 is a negative regulator of tumourigenicity, antagonizes Wnt signalling and regulates cell adhesion in colorectal cancer cell lines. PLoS One. 2011;6(7):e22733.
49. Aguilera C, Nakagawa K, Sancho R, Chakraborty A, Hendrich B, Behrens A. c-Jun N-terminal phosphorylation antagonises recruitment of the Mbd3/NuRD repressor complex. Nature. 2011;469(7329): 231-235.

50. Al-Kharusi MR, Smartt HJ, Greenhough A, et al. LGR5 promotes survival in human colorectal adenoma cells and is upregulated by PGE2: implications for targeting adenoma stem cells with NSAIDs. Carcinogenesis. 2013;34(5):1150-1157.

51. de Sousa EMF, Colak S, Buikhuisen J, et al. Methylation of cancer-stemcell-associated Wnt target genes predicts poor prognosis in colorectal cancer patients. Cell Stem Cell. 2011;9(5):476-485.

52. Sancho R, Nateri AS, de Vinuesa AG, et al. JNK signalling modulates intestinal homeostasis and tumourigenesis in mice. Embo J. 2009;28(13):1843-1854.

53. van der Flier LG, van Gijn ME, Hatzis $P$, et al. Transcription factor achaete scute-like 2 controls intestinal stem cell fate. Cell. 2009;136(5): 903-912.

54. Tanese K, Fukuma M, Yamada T, et al. G-protein-coupled receptor GPR49 is up-regulated in basal cell carcinoma and promotes cell proliferation and tumor formation. Am J Pathol. 2008;173(3):835-843.

55. Mardaryev AN, Meier N, Poterlowicz K, et al. Lhx2 differentially regulates Sox 9, Tcf4 and LGR5 in hair follicle stem cells to promote epidermal regeneration after injury. Development. 2011;138(22):4843-4852.

56. Kasper M, Jaks V, Are A, et al. Wounding enhances epidermal tumorigenesis by recruiting hair follicle keratinocytes. Proc Natl Acad Sci U S A. 2011;108(10):4099-4104.

57. da Silva-Diz V, Sole-Sanchez S, Valdes-Gutierrez A, et al. Progeny of LGR5-expressing hair follicle stem cell contributes to papillomavirusinduced tumor development in epidermis. Oncogene. 2013;32(32): 3732-3743.

58. Quigley DA, To MD, Perez-Losada J, et al. Genetic architecture of mouse skin inflammation and tumour susceptibility. Nature. 2009;458(7237):505-508

59. Van Keymeulen A, Rocha AS, Ousset M, et al. Distinct stem cells contribute to mammary gland development and maintenance. Nature. 2011;479(7372):189-193.

60. de Visser KE, Ciampricotti M, Michalak EM, et al. Developmental stage-specific contribution of LGR5(+) cells to basal and luminal epithelial lineages in the postnatal mammary gland. J Pathol. 2012;228(3):300-309.

61. Stingl J, Eirew P, Ricketson I, et al. Purification and unique properties of mammary epithelial stem cells. Nature. 2006;439(7079):993-997.

62. Shackleton M, Vaillant F, Simpson KJ, et al. Generation of a functional mammary gland from a single stem cell. Nature. 2006;439(7072): 84-88.

63. Oskarsson T, Acharyya S, Zhang XH, et al. Breast cancer cells produce tenascin $\mathrm{C}$ as a metastatic niche component to colonize the lungs. Nat Med. 2011;17(7):867-874.

64. Nakata S, Campos B, Bageritz J, et al. LGR5 is a marker of poor prognosis in glioblastoma and is required for survival of brain cancer stem-like cells. Brain Pathol. 2013;23(1):60-72.

65. Wang Y, Dong J, Li D, et al. LGR4 regulates mammary gland development and stem cell activity through the pluripotency transcription factor Sox2. Stem Cells. 2013;31(9):1921-1931.

66. Hermey G, Methner A, Schaller HC, Hermans-Borgmeyer I. Identification of a novel seven-transmembrane receptor with homology to glycoprotein receptors and its expression in the adult and developing mouse. Biochem Biophys Res Commun. 1999;254(1):273-279.

67. Shi F, Kempfle JS, Edge AS. Wnt-responsive LGR5-expressing stem cells are hair cell progenitors in the cochlea. J Neurosci. 2012;32(28): 9639-9648.

68. Chai R, Kuo B, Wang T, et al. Wnt signaling induces proliferation of sensory precursors in the postnatal mouse cochlea. Proc Natl Acad Sci U S A. 2012;109(21):8167-8172.

69. O'Brien CA, Pollett A, Gallinger S, Dick JE. A human colon cancer cell capable of initiating tumour growth in immunodeficient mice. Nature. 2007;445(7123):106-110. 
70. Mao XG, Song SJ, Xue XY, et al. LGR5 is a proneural factor and is regulated by OLIG2 in glioma stem-like cells. Cell Mol Neurobiol. 2013;33(6):851-865.

71. Goidts V, Bageritz J, Puccio L, et al. RNAi screening in glioma stemlike cells identifies PFKFB4 as a key molecule important for cancer cell survival. Oncogene. 2012;31(27):3235-3243.

72. Fischer U, Keller A, Leidinger P, et al. A different view on DNA amplifications indicates frequent, highly complex, and stable amplicons on 12q13-21 in glioma. Mol Cancer Res. 2008;6(4):576-584.

73. Barretina J, Taylor BS, Banerji S, et al. Subtype-specific genomic alterations define new targets for soft-tissue sarcoma therapy. Nat Genet. 2010;42(8):715-721.

74. Rot S, Taubert H, Bache M, et al. A novel splice variant of the stem cell marker LGR5/GPR49 is correlated with the risk of tumor-related death in soft-tissue sarcoma patients. BMC Cancer. 2011;11:429.

75. Scannell CA, Pedersen EA, Mosher JT, et al. LGR5 is Expressed by Ewing sarcoma and potentiates Wnt/beta-catenin signaling. Front Oncol. 2013;3:81.

76. Bauer L, Langer R, Becker K, et al. Expression profiling of stem cell-related genes in neoadjuvant-treated gastric cancer: a NOTCH2, GSK3B and beta-catenin gene signature predicts survival. PLoS One. 2012;7(9):e44566

77. Wu C, Xie Y, Gao F, et al. LGR5 expression as stem cell marker in human gastric gland and its relatedness with other putative cancer stem cell markers. Gene. 2013;525(1):18-25.

78. Voon DC, Wang H, Koo JK, et al. EMT-induced stemness and tumorigenicity are fueled by the EGFR/Ras pathway. PLoS One. 2013;8(8):e70427.

79. Ryuge S, Sato Y, Jiang SX, et al. The clinicopathological significance of LGR5 expression in lung adenocarcinoma. Lung Cancer. 2013;82(1): $143-148$.

80. Merlos-Suarez A, Barriga FM, Jung P, et al. The intestinal stem cell signature identifies colorectal cancer stem cells and predicts disease relapse. Cell Stem Cell. 2011;8(5):511-524.
81. Vermeulen L, Todaro M, de Sousa Mello F, et al. Single-cell cloning of colon cancer stem cells reveals a multi-lineage differentiation capacity. Proc Natl Acad Sci U S A. 2008;105(36):13427-13432.

82. Kanwar SS, Yu Y, Nautiyal J, Patel BB, Majumdar AP. The Wnt/betacatenin pathway regulates growth and maintenance of colonospheres. Mol Cancer. 2010;9:212.

83. Kemper K, Prasetyanti PR, De Lau W, Rodermond H, Clevers H, Medema JP. Monoclonal antibodies against LGR5 identify human colorectal cancer stem cells. Stem Cells. 2012;30(11):2378-2386.

84. Anastas JN, Moon RT. WNT signalling pathways as therapeutic targets in cancer. Nat Rev Cancer. 2013;13(1):11-26.

85. Takebe N, Harris PJ, Warren RQ, Ivy SP. Targeting cancer stem cells by inhibiting Wnt, Notch, and Hedgehog pathways. Nat Rev Clin Oncol. 2011;8(2):97-106.

86. Holland JD, Klaus A, Garratt AN, Birchmeier W. Wnt signaling in stem and cancer stem cells. Curr Opin Cell Biol. 2013;25(2):254-264.

87. George SR, O'Dowd BF, Lee SP. G-protein-coupled receptor oligomerization and its potential for drug discovery. Nat Rev Drug Discov. 2002;1(10):808-820.

88. Salon JA, Lodowski DT, Palczewski K. The significance of G proteincoupled receptor crystallography for drug discovery. Pharmacol Rev. 2011;63(4):901-937.

89. Jacobson KA, Costanzi S. New insights for drug design from the $\mathrm{X}$-ray crystallographic structures of G-protein-coupled receptors. Mol Pharmacol. 2012;82(3):361-371.

90. Sasaki Y, Kosaka H, Usami K, et al. Establishment of a novel monoclonal antibody against LGR5. Biochem Biophys Res Commun. 2010;394(3):498-502.

91. Schuijers J, Clevers H. Adult mammalian stem cells: the role of Wnt, Lgr5 and R-spondins. EMBO J. 2012;31(12):2685-2696.
Cancer Management and Research

\section{Publish your work in this journal}

Cancer Management and Research is an international, peer-reviewed open access journal focusing on cancer research and the optimal use of preventative and integrated treatment interventions to achieve improved outcomes, enhanced survival and quality of life for the cancer patient. The journal welcomes original research, clinical \& epidemiological

\section{Dovepress}

studies, reviews \& evaluations, guidelines, expert opinion \& commentary, case reports \& extended reports. The manuscript management system is completely online and includes a very quick and fair peerreview system, which is all easy to use. Visit http://www.dovepress.com/ testimonials.php to read real quotes from published authors. 